\title{
Normal values of flow velocity and resistance index of the ophthalmic, the central retinal, and the short posterior ciliary arteries by color Doppler ultrasound in Mexican population
}

\section{Valores normales de las velocidades de flujo e índices de resistencia de las arterias oftálmica, central de la retina y ciliares cortas posteriores por ultrasonido Doppler color en la población mexicana}

\author{
Álvaro D. Verdugo-Unigarro ${ }^{*}$, Marco A. Tobar-Marcillo ${ }^{2 *}$, Ernesto F. Martín-Biasotti ${ }^{1}$, Luis A. Padilla-Pérez ${ }^{1}$ \\ and Jorge E. Ortiz-Gallegos ${ }^{1}$
}

${ }^{1}$ Radiology and Head and Neck Imaging Service, Instituto de Oftalmología Fundación Conde de Valenciana; ${ }^{2}$ Internal Medicine Service, Hospital Regional Licenciado Adolfo López Mateos, Instituto de Seguridad y Servicios Sociales de los Trabajadores del Estado. Mexico City, Mexico

\begin{abstract}
Background: Orbital color Doppler ultrasound (DU) is a useful tool for the diagnosis of orbital vascular disease. The values in healthy patients vary depending on the geographic region; the normal values for the Mexican population are unknown. Methods: This is a non-experimental cross-sectional descriptive study; 154 patients of legal age without relevant ocular disorders or surgical history were included, who underwent a DU of both orbits to measure the maximum systolic velocity (MSV), end-diastolic velocity, and resistance index of the ophthalmic artery $(O A)$, the central retinal artery, the nasal short posterior ciliary artery, and the temporal short posterior ciliary artery (TSPCA). Results: The mean age of the population was 35.47 years and 67.5\% were women. The Kolmogórov-Smirnov test was used to determine the parametric or non-parametric distribution of the results with their respective statistical measures. There was no variation of the values regarding sex; in terms of age, we found a decrease of the MSV of both the $O A(p=0.046)$ and the temporal short posterior ciliary artery $(p=0.048)$ in patients over 50 years. Conclusions: $D U$ is highly accessible and reproducible and is useful for obtaining data on the state of orbital arterial blood flow. Since there are important differences by geographical region, it is essential to obtain our own data to study orbital disorders.
\end{abstract}

Key words: Central retinal artery. Nasal short posterior ciliary artery. Temporal short posterior ciliary artery. Ophthalmic artery. Doppler ultrasound.

\section{Resumen}

Antecedentes: El ultrasonido Doppler orbitario es útil para el diagnóstico de la enfermedad vascular orbitaria. Los valores en pacientes sanos varían dependiendo de la región geográfica; no se conocen los valores normales para la población

\section{Correspondence:}

${ }^{*}$ Marco A. Tobar Marcillo

Moras, 661

Col. del Valle, Del. Benito Juárez

C.P. 03100 , Mexico City, Mexico

E-mail: marcotobar1@ @hotmail.com Date of reception: 29-03-2020

*Álvaro D. Verdugo-Unigarro

Date of reception: 29-03-2020

Available online: 11-01-2021

E-mail: davemten@ @otmail.com

DOI: 10.24875/RMOE.M20000143

Rev Mex Oftalmol (Eng). 2021;95(1):8-14 (http://creativecommons.org/licenses/by-nc-nd/4.0/). 
mexicana. Método: Estudio no experimental de tipo descriptivo transversal. Se incluyeron 154 pacientes mayores de edad sin antecedentes patológicos ni quirúrgicos con repercusión oftalmológica, a quienes se realizó un ultrasonido Doppler de ambas órbitas para medir la velocidad sistólica máxima (VSM), la velocidad de fin de diástole y el índice de resistencia en las arterias oftálmica, central de la retina y ciliares cortas posteriores nasales y temporales. Resultados: La edad promedio de la población fue de 35,47 años y el 67,5\% eran mujeres. Sobre los valores de cada una de las mediciones realizadas se aplicó la prueba de Kolmogórov-Smirnov para determinar la distribución paramétrica o no paramétrica de los resultados con sus respectivas medidas estadísticas. No se encontró variación de los valores relacionada con el sexo, y en cuanto a la edad se encontró una disminución de la VSM de la arteria oftálmica $(p=0.046)$ y de la VSM de las arterias ciliares cortas posteriores temporales $(p=0.048)$ en los sujetos mayores de 50 años. Conclusiones: El ultrasonido Doppler es altamente accesible y reproducible, y resulta útil para obtener datos sobre el estado del flujo sanguíneo arterial orbitario. Puesto que hay diferencias importantes relacionadas con el país de procedencia, es imprescindible contar con nuestros propios datos en el estudio de patologías orbitarias.

Palabras clave: Arteria central de la retina. Arteria ciliar corta posterior nasal. Arteria ciliar corta posterior temporal. Arteria oftálmica. Ultrasonido Doppler.

\section{Introduction}

Doppler ultrasound (DU) is an imaging modality that allows the visualization of blood flow and its characteristics dynamically in real-time. This technique was described in $1979^{1,2}$ and originally had wide use in cardiology and peripheral vascular system investigations and in other solid organs such as the kidney and liver ${ }^{1-4}$. The investigation of orbit disorders with DU was described for the first time in $1989^{5}$; since then, this technique has proved valuable for the assessment of numerous ocular and orbital alterations ${ }^{6}$. However, there are few studies that determine pathological correlations, so recently, there is greater interest in the research of this imaging technique.

The most important group of disorders in which DU has proven to be useful are those that involve alterations in the hemodynamics and perfusion of the eye $\mathrm{e}^{7}$, and it is essential to improve the concepts of the pathophysiology of hypoxic-ischemic disorders of the eye and of the optic nerve, it's staging and the evaluation of the impact of various treatment modalities for these abnormalities ${ }^{3,5}$.

The analysis of the retrobulbar vessels using DU shows that hemodynamic changes develop as the age of the patients increases, showing lower flow rates and higher resistance indices in older adult patients ${ }^{8}$, as a result of vessel aging with the remodeling of the intima and media layers, which leads to loss of elasticity and arterial stiffness $^{9,10}$. In previous studies, normal values have already been determined in healthy patients in other parts of the world, such as North America ${ }^{11}$ and the United Kingdom ${ }^{12}$, and other researchers have found that there are hemodynamic variations in orbital circulation assessed by DU among patients with different ethnic origins, mainly between Europeans and Africans, and have concluded that the lower flow rates in Africans may imply a mechanism that increases the risk of glaucoma ${ }^{13,14}$. The systolic and diastolic flow velocities and the resistance indices in the retrobulbar vessels depend on multiple factors, and therefore the different pathologies that affect them will reflect the variability of the vascular hemodynamic parameters determined in the evaluation with $\mathrm{DU}^{15}$.

Articles have recently been published that describe orbital circulatory alterations caused by DU in different primary pathological states of the orbit, as well as in some systemic pathologies. However, there is little information in the literature on the hemodynamic properties of the retrobulbar circulation in the Mexican and Latino population in general, so it is relevant to determine the normality of its circulatory parameters.

\section{Methods}

\section{Study population}

A descriptive and cross-sectional study was conducted between July and November 2018 at the Instituto de Oftalmología Fundación Conde de Valenciana in Mexico City, which included 154 healthy volunteers, older than 18 years of age, of both sexes, randomly chosen, who were evaluated by an ophthalmologist. Those with a history of diabetes mellitus, hypothyroidism, hyperthyroidism, hypertension, myocardial infarction or angina pectoris, cerebral infarction or transient ischemic attack, peripheral vascular disease or claudication and hyperlipidemia, a history of cardiac or vascular surgery, a history of eye disease (except cataract or pterygium), in treatment with systemic or topical ocular medications, and of a nationality other than Mexican, were excluded from the study. 

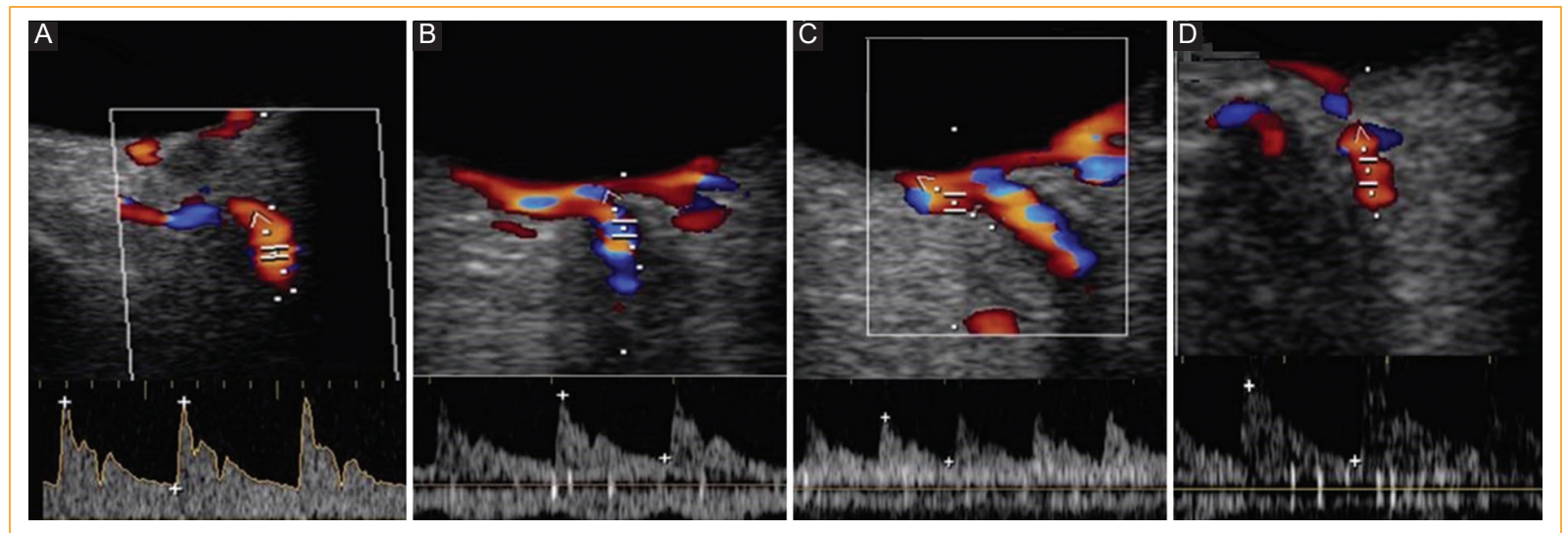

Figure 1. Color and spectral Doppler images of the ophthalmic artery (A), the central retinal artery (B), the nasal short posterior ciliary artery (C), and the temporal short posterior ciliary artery (D).

Before conducting the study, individual informed consent was obtained from all patients. The study was carried out with the authorization of the institutional research committee, with protocol number 2018.065.

\section{Procedure}

The patients were resting $15 \mathrm{~min}$ in a sitting position before performing the DU of the orbit. A Philips $₫$ ClearVue 550 Release 3.0 ultrasound machine was used with an Active Array multifrequency linear transducer from 4 to $12 \mathrm{MHz}$. The duration of each scan ranged from 30 to $40 \mathrm{~min}$, with the patient in the supine position, and the transducer was gently applied to the closed upper eyelid without exerting pressure when coupled with a small amount of conductive gel.

Preliminary B-mode scans were performed in horizontal and vertical planes through the eye as a screening procedure. The vessels were identified in color Doppler, a sample volume of $0.5 \mathrm{~mm}$ was used, and the Doppler angle was adjusted to the vessels before obtaining the spectrum. To ensure accurate information on the velocities, the Doppler angle was not adjusted to more than $60^{\circ}$, since with larger values, the small variations in the assignment of the flow direction translate into large variations in the estimate of velocity. Spectral Doppler waveforms were recorded and information was collected from the ophthalmic artery $(\mathrm{OA})$, the central retinal artery (CRA), the nasal short posterior ciliary artery (NSPCA), and the temporal short posterior ciliary artery (TSPCA); obtaining the maximum systolic velocity (MSV), the end-diastolic velocity (EDV) and the resistance index (RI).

\section{Statistical analysis}

The SPSS Version 25 program was used for data tabulation and the analysis of the results. We included qualitative variables in frequency tables, and we established the distribution of quantitative variables by means of the Kolmogorov-Smirnov test. When the value of this test was $<0.07$, it was adjusted by Lilliefors. For these tests, the null hypothesis corresponds to the fact that the variables present a non-parametric distribution, and the alternate hypothesis corresponds to the opposite. For variables with a parametric distribution, the mean and standard deviation were estimated, and for variables with a non-parametric distribution, the median, the $5^{\text {th }}$ and $95^{\text {th }}$ percentiles, and the upper and lower limits were estimated. The results of the flows and the resistance indices in each one of the evaluated arteries were represented in $\mathrm{Q}-\mathrm{Q}$ graphs.

\section{Results}

We included 154 patients with bilateral orbital exploration, a total of 308 examinations, and there was no lost data. Age had a non-parametric distribution, with a mean of 35.48 years and a median of 32 years. Of all patients, $67.5 \%$ (52) were women.

The DU study was carried out in the four arterial territories described (Fig. 1), the results presented in table 1, classifying the MSV and EDV, and the RI in each of the arteries evaluated. To know the distribution of the values in each of the variables, the Kolmogorov-Smirnov test was applied, and when its value was $<0.07$, it was adjusted by Lilliefors; the application of the two 
Table 1. Values obtained by Doppler ultrasound of maximum systolic velocity (MSV), end-diastole velocity (EDV), and resistance index (RI) of the ophthalmic artery (OA), the central retinal artery (CRA), the nasal short posterior ciliary artery (NSPCA), and the temporal short posterior ciliary artery (TSPCA)

\begin{tabular}{|l|l|l|l|l|l|l|l|l|l|}
\hline & Mean & Median & SD & $P 5$ & $P 95$ & $\begin{array}{c}\text { Lower } \\
\text { limit }\end{array}$ & $\begin{array}{c}\text { Upper } \\
\text { limit }\end{array}$ & $\begin{array}{c}\text { Ksymptotic } \\
\text { test } \\
\text { significance }\end{array}$ \\
\hline MSV OA $\left(\mathrm{cm} / \mathrm{s}^{2}\right), \mathrm{n}=308$ & 33.101 & 31.632 & 8.812 & 21.47 & 50.83 & 15.72 & 55.60 & 0.095 & $<0.001$ \\
\hline EDV OA $\left(\mathrm{cm} / \mathrm{s}^{2}\right), \mathrm{n}=308$ & 8.824 & 8.267 & 3.271 & 4.52 & 13.77 & 3.12 & 19.90 & 0.082 & $<0.001$ \\
\hline RI OA, $\mathrm{n}=308$ & 0.734 & 0.741 & 0.067 & 0.626 & 0.837 & 0.55 & 0.86 & 0.052 & $0.046^{*}$ \\
\hline MSV CRA $\left(\mathrm{cm} / \mathrm{s}^{2}\right), \mathrm{n}=308$ & 12.138 & 11.952 & 2.942 & 7.27 & 16.57 & 5.26 & 21.70 & 0.041 & $0.200^{*}$ \\
\hline EDV CRA $\left(\mathrm{cm} / \mathrm{s}^{2}\right), \mathrm{n}=308$ & 4.283 & 4.127 & 1.421 & 2.18 & 6.65 & 1.69 & 8.61 & 0.087 & $<0.001$ \\
\hline RI CRA, $\mathrm{n}=308$ & 0.655 & 0.661 & 0.074 & 0.522 & 0.769 & 0.39 & 0.80 & 0.047 & $0.094^{*}$ \\
\hline MSV NSPCA $\left(\mathrm{cm} / \mathrm{s}^{2}\right), \mathrm{n}=308$ & 11.034 & 10.800 & 2.440 & 7.41 & 15.50 & 5.95 & 17.4 & 0.054 & $0.030^{*}$ \\
\hline EDV NSPCA $\left(\mathrm{cm} / \mathrm{s}^{2}\right), \mathrm{n}=308$ & 4.627 & 4.283 & 1.454 & 2.59 & 7.51 & 2.02 & 8.31 & 0.094 & $<0.001$ \\
\hline RI NSPCA, $\mathrm{n}=308$ & 0.584 & 0.578 & 0.077 & 0.452 & 0.712 & 0.65 & 0.77 & 0.083 & $<0.001$ \\
\hline MSV TSPCA $\left(\mathrm{cm} / \mathrm{s}^{2}\right), \mathrm{n}=308$ & 11.530 & 11.195 & 2.822 & 7.68 & 16.64 & 6.42 & 18.30 & 0.064 & $0.004^{*}$ \\
\hline EDV TSPCA $\left(\mathrm{cm} / \mathrm{s}^{2}\right), \mathrm{n}=308$ & 5.006 & 4.715 & 1.833 & 2.66 & 8.40 & 1.80 & 10.00 & 0.080 & $<0.001$ \\
\hline RI TSPCA, $\mathrm{n}=308$ & 0.569 & 0.564 & 0.097 & 0.419 & 0.736 & 0.36 & 0.81 & 0.051 & $0.049 *$ \\
\hline
\end{tabular}

SD: standard deviation; K-S: Kolmogorov-Smirnov; P: percentile.

*Lilliefors significance correction.
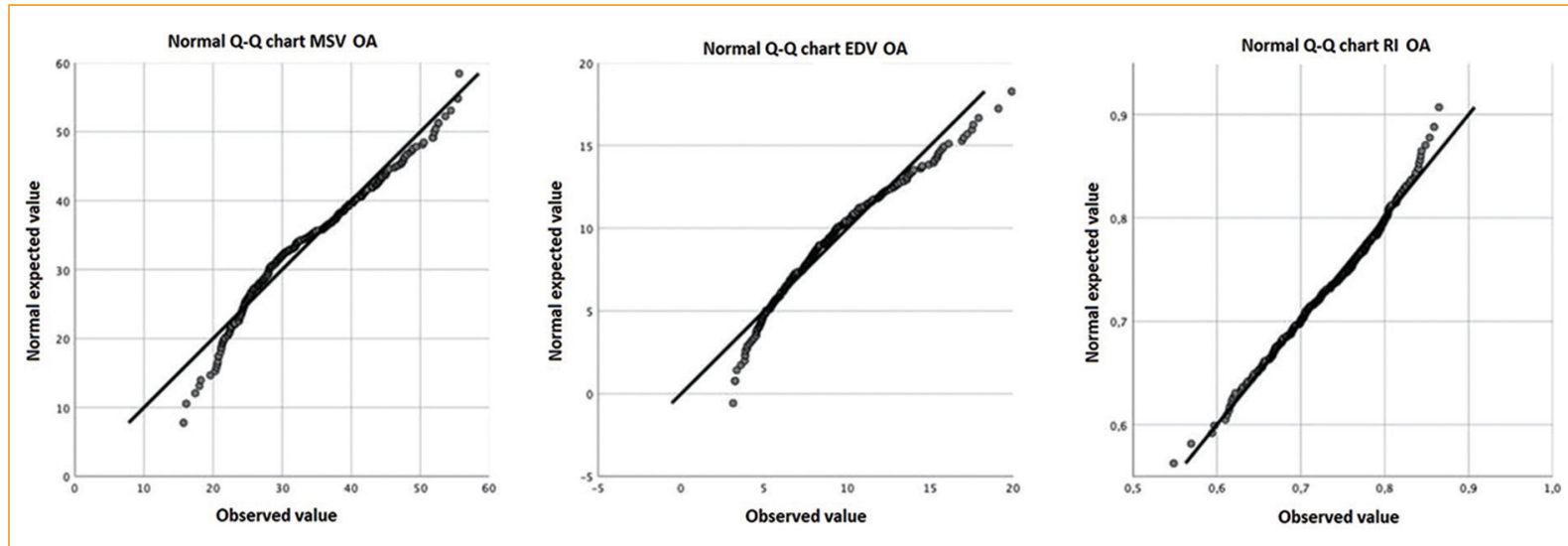

Figure 2. 0-0 graph showing the distribution of the values of maximum systolic velocity, end-diastolic velocity, and resistance index of the ophthalmic artery.

tests allowed rejecting the null hypothesis with a significance of $95 \%$ in the distribution of two variables, the MSV of the CRA with a mean of $12.134 \pm 2.942 \mathrm{~cm} / \mathrm{s}^{2}$ and the RI of the CRA with a mean of $0.655 \pm 0.074$; the rest of the variables showed a non-parametric distribution and the median, upper and lower limits, and the $5^{\text {th }}$ and $95^{\text {th }}$ percentiles were applied as measurement methods.
In figure 2, a $Q-Q$ graph shows the distribution of the observed and expected values for a normal distribution of MSV, EDV, and RI in the OA. In figure 3, using the same $Q-Q$ graph, the distribution of said values in the CRA is expressed and the correlation between the observed and expected values for the MSV and the RI is identified; these variables are the ones that showed a parametric distribution. Figures 4 and 5 show the 


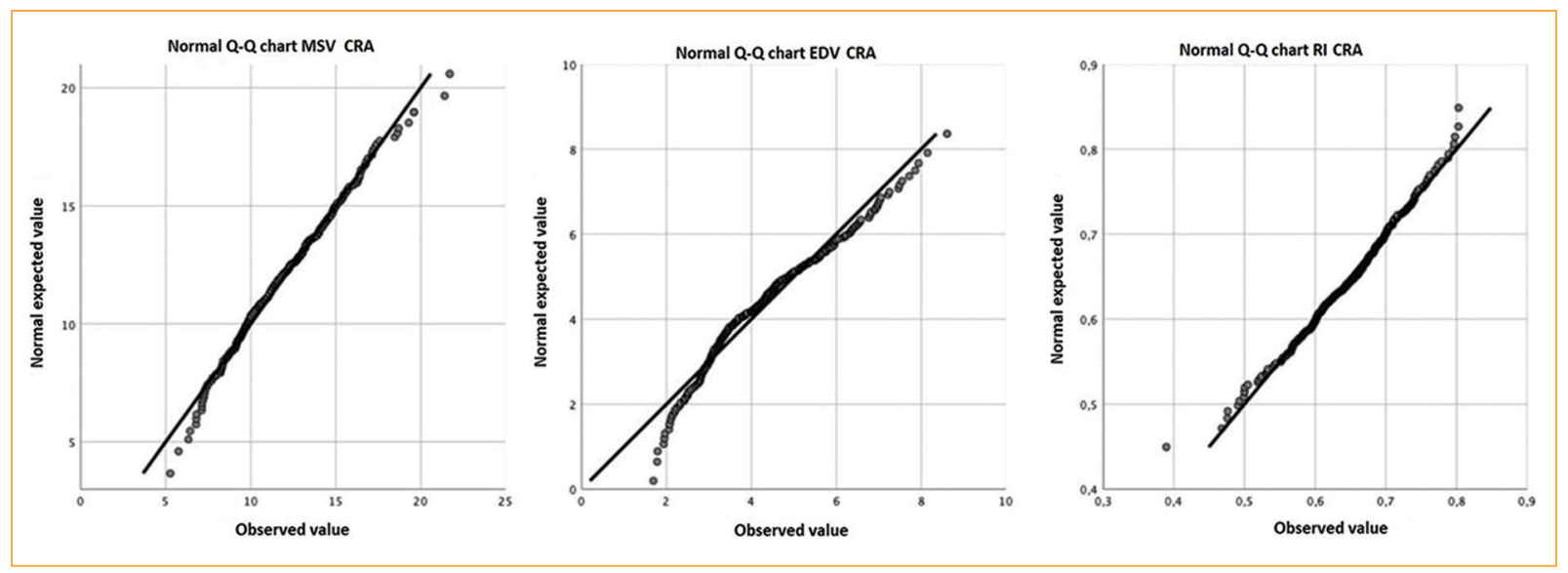

Figure 3. Q-0 graph showing the distribution of the values of maximum systolic velocity, end-diastolic velocity, and resistance index of the central retinal artery.

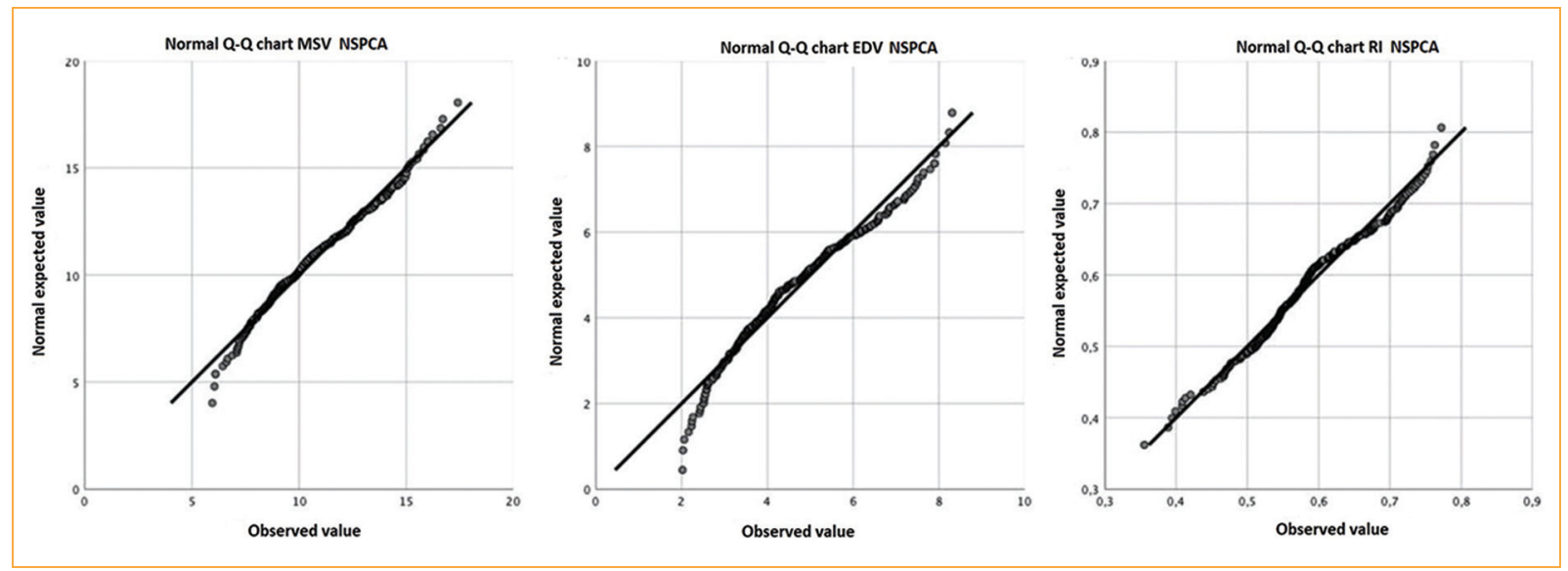

Figure 4. Q-0 graph showing the distribution of maximum systolic velocity, end-diastolic velocity, and resistance index of the nasal posterior short ciliary artery.

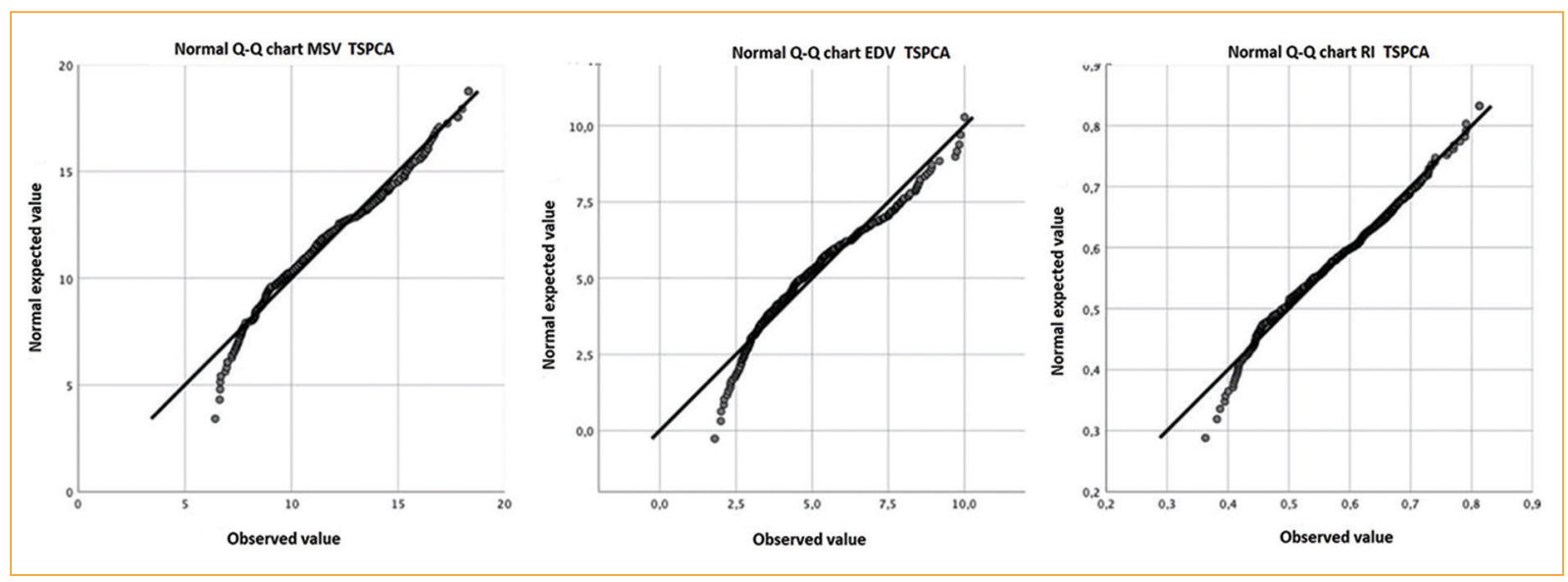

Figure 5. 0-0 graph showing the distribution of the values of maximum systolic velocity, end-diastolic velocity, and resistance index of the temporal short posterior ciliary artery. 
distribution of the variables corresponding to the NSPCA and the TSPCA, respectively.

Regarding age distribution, 24 (15.6\%) patients were $\geq 50$ years old. Through a mean difference with a t-test, it was established that they had a lower MSV in the OA $(p=0.046)$ and a lower MSV in the TSPCA $(p=0.048)$ compared with patients under 50 years of age. In the rest of the measurements, no significant difference was reached, and in the same way, the distribution by sex showed no significant differences in the values obtained.

\section{Discussion}

Doppler flow analysis of retrobulbar vessels using DU is a useful way to determine orbital, ocular, central nervous system, and systemic vascular pathology. For this, it is important to have normal values of MSV, EDV, and $\mathrm{RI}$ adjusted for the population under examination since there is evidence that shows significant changes in these values depending on the place of origin, as shown in a study that compared 24 patients of African descent and 34 patients of European descent, indicating that the latter has higher EDV and RI values, without differences in MSV in the four arteries examined ${ }^{13,14}$. When comparing these values with those of our sample, we observed that Mexican patients show higher flow velocities with lower Rls. However, when comparing them with other registries of healthy patients, important variations are found: a study in a Canadian population ${ }^{11}$ that evaluated the $\mathrm{OA}$ flows in 60 patients showed an MSV of $45.1 \pm 7.8 \mathrm{~cm} / \mathrm{s}^{2}$ and an EDV of $12.0 \pm 3.4 \mathrm{~cm} / \mathrm{s}^{2}$, greater than those observed in our patients, and another study carried out in the United Kingdom ${ }^{12}$ with 80 healthy patients, measured flow velocities and RIs in the four arteries explored in our study, and similarly found significantly higher MSV and EDV in the OA, with no variation in velocities in the CRA, NSPCA, and TSPCA.

There is a variation of some values with respect to the age of the patients. Modrzejewska et al. ${ }^{8}$ included 162 healthy patients, divided into five groups according to age, and in the group of patients aged $68-80$ years, a reduced MSV and MDV were observed in the CRA, as well as an increased $R I$ in the OA, the CRA, the NSPCA, and the TSPCA. These differences are related to the vascular changes typical of senescence, consisting of sclerosis of the arterial walls. In our analysis, which involved a larger number of patients, we only found a significant reduction of the MSV in the OA and TSPCA.
Regarding the distribution by sex, a study with 128 patients found a reduced MDV in older women ${ }^{16}$. No significant differences were found in the measurement according to sex, even adjusting for age.

Finding these differences between our results and those reported in the international literature allows us to establish the normal parameters in the Latino population, specifically in the Mexican population.

With this tool, we can better study prevalent pathologies, such as thyroid orbitopathy, which has demonstrated hemodynamic changes in the superior ophthalmic vein as a marker of venous stasis in this disorder ${ }^{17}$. Although orbital arterial flow has been less studied, it is a marker of endothelial injury that manifests itself by increased flow velocities and RIs ${ }^{18}$. It has also been observed that diabetic patients, especially those most affected by diabetic retinopathy, have lower MSV and EDV in the CRA, with higher RIs in both the CRA and the $O A^{19}$. Some authors argue that one of the causes of glaucoma is of vascular origin, a fact that has become important in recent years, and evaluation by DU has proven to be a very useful tool. The ultrasound findings that support this theory are a decrease of the EDV in the CRA and an increase in the RIs of the NSPCA and the TSPCA in the acute phase of the disease, while in the chronic phase, a marked decrease in the MSV and the EDV has been identified in both the NSPCA and the TSPCA, changes that are associated with disease progression ${ }^{20-22}$.

\section{Conclusion}

DU is an accessible, reproducible, and low-cost tool, useful for obtaining data on flow velocities and RIs of the orbital arteries. The present study corroborates the findings presented in other series, such as the decrease in MSV and EDV and the increase of the RI as patient's age increases. Furthermore, we found that in the Mexican population, there are lower values of MSV and EDV compared to other populations, without finding a factor that determines these changes.

Therefore, it was of great importance for the study of ocular pathologies prevalent in our environment, to establish the normal values for the Mexican population that allow us to make a better evaluation and diagnosis. More studies involving patients from other parts of Mexico and from other Latin American countries are required. 


\section{Conflicts of interest}

The authors declare no conflicts of interest.

\section{Ethical disclosures}

Protection of human and animal subjects. The authors declare that the procedures followed were in accordance with the regulations of the relevant clinical research ethics committee and with those of the Code of Ethics of the World Medical Association (Declaration of Helsinki).

Confidentiality of data. The authors declare that they have followed the protocols of their work center on the publication of patient data.

Right to privacy and informed consent. The authors have obtained the written informed consent of the patients or subjects mentioned in the article. The corresponding author is in possession of this document.

\section{References}

1. Mitchell DG. Color Doppler imaging: principles, limitations, and artifacts. Radiology. 1990;177:1-10.

2. Aburn NS, Sergott RC. Orbital colour Doppler imaging. Eye. 1993;7:639-47

3. Foley WD. Vascular ultrasound: a radiologist perspective. Echocardiography. 1992;9:537-45

4. McNaughton DA, Abu-Yousef MM. Doppler US of the liver made simple. RadioGraphics. 2011;31:161-88.

5. Erickson SJ, Hendrix LE, Massaro BM, Harris GJ, Lewandowski MF, Foley WD, et al. Color Doppler flow imaging of the normal and abnormal orbit. Radiology. 1989;173:511-6.

6. Guthoff RF, Berger RW, Winkler P, Helmke K, Chumbley LC. Dopple ultrasonography of the ophthalmic and central retinal vessels. Arch Ophthalmol. 1991;109:532-6.
7. Stalmans I, Vandewalle E, Anderson DR, Costa VP, Frenkel RE, Garhofer $\mathrm{G}$, et al. Use of colour Doppler imaging in ocular blood flow research. Acta Ophthalmol. 2011;89:e609-30.

8. Modrzejewska M, Siesky B, Amireskandari A, Holland S, Grzesiak W, Zaborski D, et al. Parameters characterizing age-dependent retrobulbar circulation in healthy subjects measured by color Doppler ultrasonography. Curr Eye Res. 2015;40:729-36.

9. Bolton E, Rajkumar C. The ageing cardiovascular system. Rev Clin Gerontol. 2011;21:99-109.

10. O'Rourke MF, Hashimoto J. Mechanical factors in arterial aging: a clinical perspective. J Am Coll Cardiol. 2007;50:1-13.

11. Rojanapongpun $P$, Drance SM. Velocity of ophthalmic arterial flow recorded by Doppler ultrasound in normal subjects. Am J Ophthalmol. 1993; $115: 174-80$

12. Baxter GM, Williamson TH. Color Doppler imaging of the eye: normal ranges, reproducibility, and observer variation. J Ultrasound Med. 1995;14:91-6.

13. Kaskan B, Ramezani K, Harris A, Siesky B, Olinde C, WuDunn D, et al. Differences in ocular blood flow between people of African and European descent with healthy eyes. J Glaucoma. 2016;25:709-15.

14. Siesky B, Harris A, Racette L, Abassi R, Chandrasekhar K, Tobe LA, et al. Differences in ocular blood flow in glaucoma between patients of African and European descent. J Glaucoma. 2015;24:117-21.

15. Erickson SJ, Hendrix LE, Massaro BM, Harris GJ, Lewandowski MF, Foley WD, et al. Color Doppler flow imaging of the normal and abnormal orbit. Radiology. 1989;173:511-6.

16. Harris A, Harris M, Biller J, Garzozi H, Zarfty D, Ciulla TA, et al. Aging affects the retrobulbar circulation differently in women and men. Arch Ophthalmol. 2000;118:1076-80.

17. Monteiro ML, Angotti-Neto HA, Benabou JE, Betinjane AJ. Color Dopple imaging of the superior ophthalmic vein in different clinical forms of Graves' orbitopathy. Jpn J Ophthalmol. 2008;52:483-8.

18. Gonçalves AC, Gebrim EM, Monteiro ML. Imaging studies for diagnosing Graves' orbitopathy and dysthyroid optic neuropathy. Clinics (Sao Paulo). 2012;67:1327-34.

19. Meng N, Liu J, Zhang Y, Ma J, Li H, Qu Y. Color Doppler imaging analysis of retrobulbar blood flow velocities in diabetic patients without or with retinopathy: a meta-analysis. J Ultrasound Med. 2014;33:1381-9.

20. Gherghel D, Orgül S, Gugleta K, Gekkieva M, Flammer J. Relationship between ocular perfusion pressure and retrobulbar blood flow in patients with glaucoma with progressive damage. Am J Ophthalmol. 2000;130:597-605.

21. Ehrlich R, Harris A, Siesky BA, Moss AM, Ramanathan M, Pickett MA, et al. Repeatability of retrobulbar blood flow velocity measured using color Doppler imaging in the Indianapolis Glaucoma Progression Study. J Glaucoma. 2011;20:540-7.

22. Srikanth K, Kumar MA, Selvasundari S, Prakash ML. Colour Dopple imaging of ophthalmic artery and central retinal artery in glaucoma patients with and without diabetes mellitus. J Clin Diagn Res. 2014;8:VC01-2. 